\title{
Design of Wearable shoe for blind using LIFI Technology
}

\author{
V. Vijeesh, E. Kaliappan, B. Ponkarthika, G.Vignesh
}

\begin{abstract}
Being independent in the existing world is crucial for a visually impaired person. There are about 36 million blind people all over the world. The main purpose of the project is to reduce the difficulties faced due to blindness. This proposed system hypothesizes a smart shoe that alerts visually impaired people over obstacles that could help them to walk independently with low chances of accident. Recently, many devices such as smart cane with advanced technology were introduced to assist the visually impaired for safe and independent walking. To overcome the limitation, a smart shoe is designed and developed to detect obstacles in the path of visually impaired person which will make them feel like a normal individual. This proposed system mainly focuses on LiFi technology that helps to identify the locations as they pass through the places. Introducing smart shoe which will assist them in their motion and other needed activities. It supports LiFi with reliable communication and navigation system during the dark. Information is provided as voice playback to the user. Thus, the user can navigate independently just by using the voice commands provided by the device. A wireless setup is provided at the places which are often used by the person in order to specify the person is reached the required place.
\end{abstract}

Keywords: DF mini player, Electronic Travel Aids, smart shoe, ultrasonic sensor.

\section{INTRODUCTION}

vision is the most important sense to help us understand and perceive the world around us. It delivers a feedback mechanism with the interconnection for a stable interaction with the environment and it consolidated the vision. Loss of vision is a major challenge for a normal living life of an individual. It becomes an unpropitious affect in terms of physical, social, psychological and balanced life.

According to the World Health Organization (WHO), the estimated people who are visually impaired are around 285 million, of whom 39 million are suffering from blindness. Usually, visually impaired people prefer a long cane or a guide dog to assist their way on the daily life basis. An assistive cane is a stick which is used to improve the stability during the walk and it also gives the information about the ground levels. On the other side, a guide dog helps by avoiding obstacles and signals in the situation of traffic. Most of the visually impaired persons may not be in a situation to afford a guide dog. However, both long cane and a guide dog does not provide much information about the dangers in all the three different directions.

Revised Manuscript Received on 14 August, 2019.

V.Vijeesh, EEE department, Easwari Engineering College, Chennai, Tamil Nadu, India.(Email: vijeesh.vj158@gmail.com)

Dr.E.Kaliappan, EEE department, Easwari Engineering College, Chennai, Tamil Nadu India(.Email: ekn.eee@gmail.com)

B.Ponkarthika, EEE department, Easwari Engineering College, Chennai, Tamil Nadu India.(Email: karthikalai57@gmail.com)

G.Vignesh, EEE department, Easwari Engineering College, Chennai, Tamil Nadu India.(Email: vignesh.g@eec.srmrmp.edu.in)
Various researches are being conducted to improve the quality of the life for visually impaired people. Many Electronic Travel Aids (ETAs) are provided for enhancing mobility for the visually impaired and blind people. However, there does not exist such device for the mobility of travelling using light in which the rate of transmission through light is 100 times faster than that of a basic Wifi.A smart shoe is an electronic device that can be used for navigation for both indoor and outdoor applications by the visually impaired persons. The smart shoe consists of the components like ultrasonic sensor, water level sensor that helps for the detection of the obstacles. The ultrasonic sensor will continuously transmit signals, when an obstacle is detected these echo signals will get back to the receiver sensor. The user will be warned about the presence of the obstacles. The ultrasonic sensor detects the presence of an obstacle around a distance of $0.3 \mathrm{~m}$. It detects in range of ( 0 180) degrees.

The shoe supports $\mathrm{LiFi}$ technology with reliable communication and navigation system during the dark. The use of LiFi technology is the major addition for the shoe. The LiFi technology transmits the information at a faster rate. When a LED light is turned $\mathrm{ON}$, the information gets transmitted through the LiFi Transmitter and the data is received through $\mathrm{LiFi}$ receiver. The received data will contain information about the data. A smart shoe that provides a stable navigation helps to alert the visually impaired person over obstacles that could help then to move independently with low chance of accidents without the help of cane.

\section{II.BLOCK DIAGRAM AND COMPONENT DESCRIPTION}

In today's world visually challenged people find it difficult for their navigation. Safety is the factor that has to be considered for the visually impaired and blind pedestrians during their movement.

According to recent findings, there are various Electronic Travel Aids (ETAs) that has been developed for the visually impaired people. Apart from that, the guide dogs are also used by the blind people for their locomotion. But all these proposed system has also certain limitations that reduces the systems efficiency. The use of long cane is good as it is inexpensive but it has some limitations. In the case of a guide dog, the feedback is good but it is costly and the person has to be experienced to handle the dog. The usage

Blue Eyes Intelligence Engineering

\& Sciences Publication 
of the sonic path finder does not provide the accurate path and it also fails to find the position of the obstacles.

The navigation system that is based on optical peacans will not be able to provide any information regarding the shape and motion of the obstacles. Hence, the visually impaired person finds it difficult to move from one place to another without the help of other individuals. Hence in order to overcome all these limitations a smart shoe is developed that helps the visually impaired and blind persons to feel independent and normal. It also helps them to identify the location using LiFi technology.

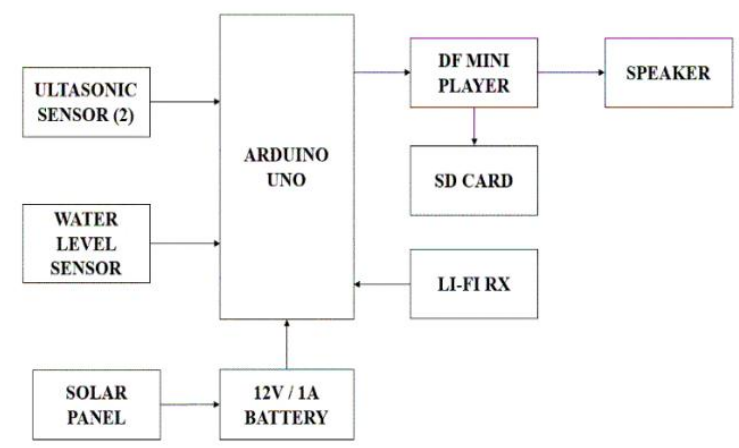

Fig.1. Block diagram of shoe module

The shoe module shown in Fig 1 has the ultrasonic sensor, which detects the presence of obstacles in the path. The water level sensor detects the presence of water. The sensors then sends the output to the controller, which warns the blind through the DF Mini Player. The speaker warns the blind. The Shoe Module contains:

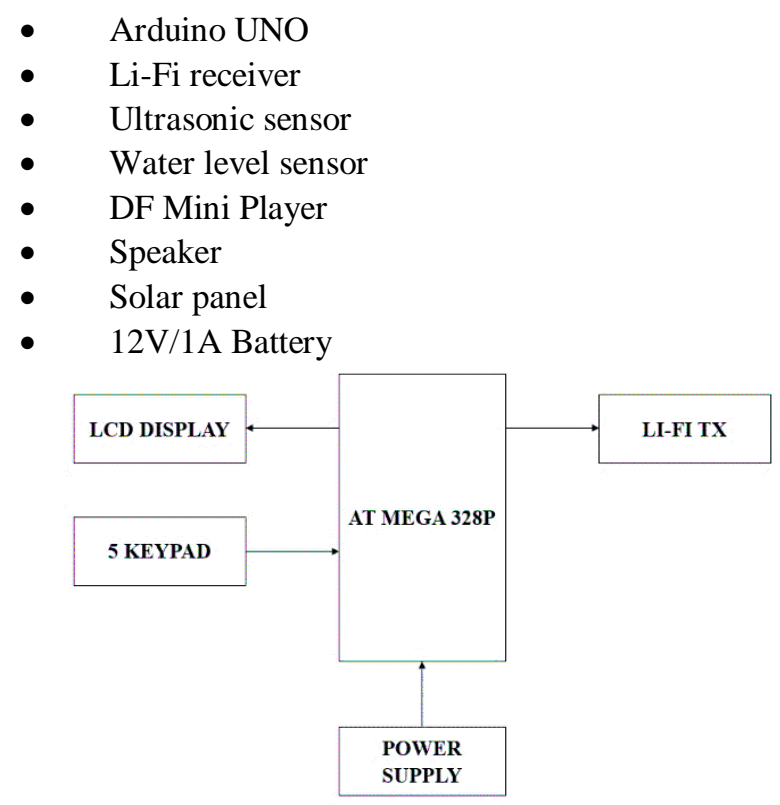

Fig.2. Block Diagram of Li-Fi Module

The Li-Fi module shown in Fig 2 contains the LED connected to the controller. The 5 keypad is used to send different data through the LED. The LCD displays the data being transmitted. The Li-Fi module contains

$\begin{array}{ll}\text { - } & \text { At mega 328p } \\ \text { - } & \text { Li-Fi Transmitter } \\ \text { - } & \text { LCD } \\ & 5 \text { Keypad }\end{array}$

\section{LITERATURE SURVEY}

M F Saaid, A M Mohammad, M S AMegat Ali [1] has developed a smart cane with a range notification for the visually challenged people. As the blind people always get knocked by the obstacles they find it difficult to lead a normal life and they are being dependent on others. This project designs a smart cane that consists of an ultrasonic sensor that helps in detecting the presence of an obstacle. When an obstacle is detected a beeping sound will be heard to the person through the earphones. The main disadvantage of this system is that when the person swings the cane the position of ultrasonic sensor gets affected and it reduces the efficiency of the system.Yeong-Hwa Chang, NilimaSahoo and Hung-Wei Lin [2] all worked together to develop an intelligent walking stick for the blind people. This walking stick consists of various sensors, Raspberry Pi and PIC as the controller. It also uses Global Positioning System (GPS) that helps to identify the location. The usage of ultrasonic sensor helps to detect the obstacles while walking. The water level sensor detects the presence of wet surface at the knee level. The main usage of raspberry $\mathrm{Pi}$ is that it provides with WI-FI and Bluetooth facilities. Even though this walking stick provides various features it has a disadvantage of using GPS as it fails to guide the visually challenged people in a proper way.

ZeeshanSaquib, VishakhaMurari, Suhas N Bhargav[3] has done a work to develop a Smart Electronic Travelling Aid (ETA) called BlinDAR for the visually challenged people. The Blinder mainly uses ultrasonic sensors for the detection of obstacles. WI-FI and GPS module is used to identify the location. The presence of can be detected by using MQ2 gas sensor .If the stick is misplaced it can be easily found with the help of RF TX/RX module connected to the stick. The Blinder is highly reliable, low power, light weight and fast responding travelling aid. The main drawback of this device is that it is not cost efficient.

ArneshSen, KaustavSen, JayotiDas [4] worked together to develop an ultrasonic blind stick foot visually challenged people. This ultrasonic blind stick consists of an artificial navigating system with adjustable sensitivity. By using an ultrasonic proximity sensor and a GPS module helps the blind people to walk independently. The main disadvantage of this stick is that the sensing accuracy gets affected by the change in temperature of 10 degrees or more.Akhilesh Krishnan, DeepakrajG ,Nishanth N, Dr.K.M.Anandkum[5] has resulted in the development of an Autonomous walking stick for the visually challenged people. This Walking stick mainly uses the techniques of echo-location and image processing with the help of ultrasonic sensors the obstacles present in front of the person. The only disadvantage of this system is the charge capacity of the device.Guojun Yang and JafarSaniie [6] has proposed a system for indoor navigation for the blind system. In the work they mainly use augmented reality markers that helps in indoor navigation for the visually challenged people. It is more efficient only in indoor and it is not useful in outdoor applications.

EvangelosPikasis and Wasiu O Popoola [7] has done a 
work to understand the LI-FI effect on LED light quality. The proposed model helps us to determine the expected changes that occurs in the light quality due to various light modulation techniques. Mahendran [8] has discussed about the integrated LI-FI for smart communication through illumination. When a LED light bulb is turned ON the transmission of the data takes place through the LI-FI technology. It helps to overcome the disadvantages caused during the transmission of data through electromagnetic waves.

Kailas Patil [9] has proposed and developed an electronic aid for the visually impaired people. This aid is called as a Navguide device. It mainly uses various ultrasonic sensors and motors that helps to control the sensors.All the sensors are connected in a shoe and it helps the visually challenged people to move independently without being knocked by the obstacles .The Navguide is cheaper and a light weight device. The design of smart walking stick for visually challenged people [10]. It makes use of navigation system that helps for the movement of the blind people. It is cost efficient and with the help of the navigation the blind people can have an independent without the help of other people.

\section{CASE STUDY, RESULT AND ANALYSIS}

This section deals with the case study which involves the visually impaired people. This case study took place at a "Blind Home". It helped to know about the difficulties faced by the people to live a normal life in this world.

Survey of suggestions insisted by the visually impaired people:

The table 1 shows the list of visually impaired and blind person with whom the survey and discussions where made regarding there difficulties faced in the surroundings and the society.

Table-I: List of suggestions given by the visually impaired persons

\begin{tabular}{|c|l|l|l|}
\hline Sl.No & $\begin{array}{c}\text { Name Of } \\
\text { The Person }\end{array}$ & Age & Suggestions \\
\hline 1. & Barani & 21 & $\begin{array}{c}\text { To detect the } \\
\text { obstacles }\end{array}$ \\
\hline 2. & Gopi & 17 & $\begin{array}{c}\text { To reach the } \\
\text { destination point }\end{array}$ \\
\hline 3. & S.Nanthakumar & 19 & $\begin{array}{c}\text { To identify the } \\
\text { obstacles }\end{array}$ \\
\hline 4. & C.Manokaran & 19 & $\begin{array}{c}\text { To identify the } \\
\text { name of the shop }\end{array}$ \\
\hline 5. & A.Aravindhan & 20 & $\begin{array}{c}\text { To reach the } \\
\text { destination point }\end{array}$ \\
\hline 6. & Marimuthu & 19 & $\begin{array}{c}\text { To identify the } \\
\text { bus number }\end{array}$ \\
\hline 7. & K.Kalaivaanan & 18 & $\begin{array}{c}\text { To identify the } \\
\text { shop }\end{array}$ \\
\hline 8. & S.Selvaraj & 22 & $\begin{array}{c}\text { To identify the } \\
\text { bus number }\end{array}$ \\
\hline 9. & Vijay & 21 & $\begin{array}{c}\text { To detect the } \\
\text { obstacles }\end{array}$ \\
\hline 10. & Raja & 0 & $\begin{array}{c}\text { To identify the } \\
\text { bus numbers }\end{array}$ \\
\hline
\end{tabular}

The working model setup was obtained as shown in Fig. The following results were executed according to the objective of our project. The shoe model consists of Arduino UNO controller which is integrated with ultrasonic sensor, water level sensor, $\mathrm{Li}-\mathrm{Fi}$ receiver, $\mathrm{DF}$ mini player and speaker. The Li-Fi model consists of $\mathrm{Li}-\mathrm{Fi}$ transmitter, five keypad and LED. All those components work together through the controller to provide reliable navigation and safe mobility.

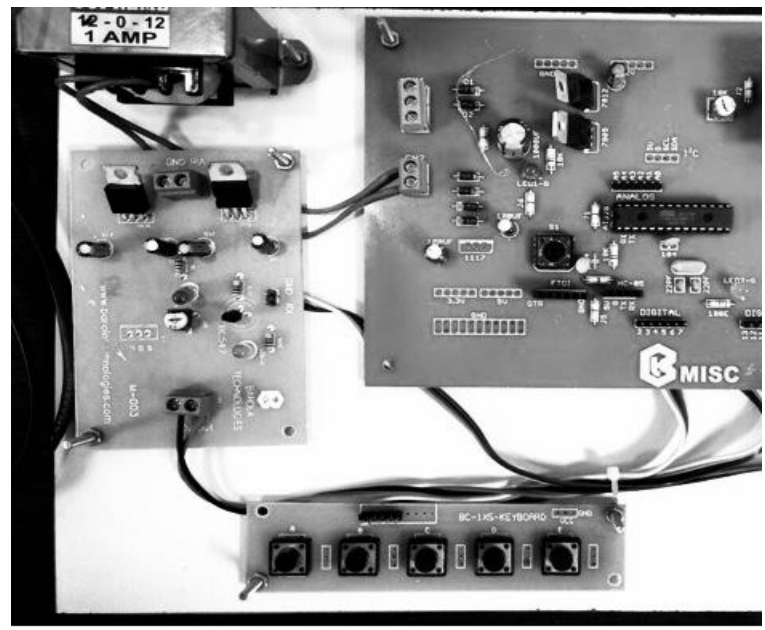

Fig.3. Receiver Section

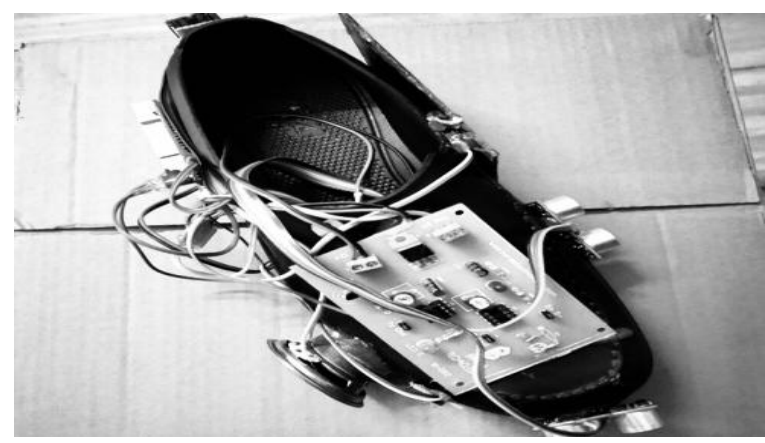

Fig.4.Final prototype model of smart shoe with $\mathrm{Li}-\mathrm{Fi}$ technology

\section{CONCLUSION}

This paper mainly focuses on safe mobility and reliable navigation which would provide ease to visually-imapired person in many circumstances, such as travelling, shopping and other day today activities. The usage of Smart Shoe makes them independent in the society. The smart shoe helps them to feel normal and it also increases their confidence level in the society that would help them to lead a normal life. With the help of Li-Fi technology it helps the people to identify the location and to make their movement comfortable. This Li-Fi technology also helps to identify the bus number that would help the blind people to make their travel easier. Though this paper is only suitable for blind friendly society, many improvements in technology could make this more cost efficient and user friendly in terms of usability and portabillity

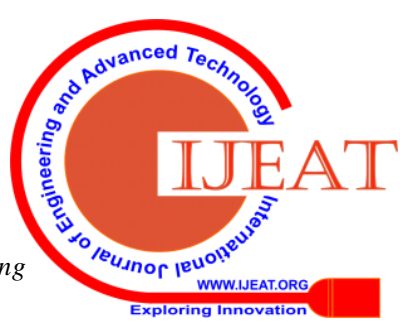




\section{REFERENCES}

1. M F Saaid, A M Mohammad, M S AMegatAli, "Smart Cane with Range Notification for Blind people", I2CACIS, 22 October 2016, Shah Alam, Malaysia.

2. Yeong-Hwa Chang, NilimaSahoo and Hung-Wei Lin, "An Intelligent walking stick for the visually challenged people". IEEE ICAST 2018-Meen, Prior\&Lam 2018.

3. Zeeshan Singh, VishakhaMurari, Suhas N Bhargav, "BlinDar :An Invisible Eye for the blind people(IOT)", making life easy for the blind with internet of things, May2017.

4. ArneshSen, KaustavSen, Jayoti Das, "Ultrasonic Blind Stick For Completely Blind People To avoid any Kind of obstacles".

5. Akhilesh Krishnan, Deepakraj G ishanth N Dr K M Anandkumar", Autonomous Walking Stick For The Blind Using Echolocation And Image Processing".

6. Guojun Yang and JafarSanii, "Indoor navigation for visually impaired using AR Markers". Department of Electrical and Computer Engineering, 51-60,2017.

7. EvangelosPikasis and Wasiu O Popoola, "Understanding LiFi Effect on LED Light Quality".

8. R Mahendran, "IntergratedLifi (Light Fidelity) For Smart Communication Through Illumination", ICACCCT 2016.

9. Kailas Patel, QaidjoharJawadwala, Felix CheShu, "Design and Construction of Electronic Aid for Visually Impaired People”, 5052,2018 .

10. SauravMohapatra,Subham Rout, VarunTripathi, TanishSaxena, YepugantiKaruna, "Smart walking Stick for the Blind integrated with SOS Navigation System.” IEEE Xplore, ICOEI2018

\section{AUTHORS PROFILE}

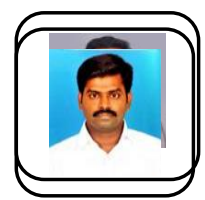

V.Vijeesh, working as an Assistant Professor in the Department of Electrical and Electronics Engineering, Easwari Engineering College, Chennai, Tamil Nadu, India .He received his B.E degree in Electrical and Electronics Engineering from Noorul Islam College of Engineering, M.E. degree in Power system engineering from Government College of Technology, Coimbatore, India. He has published over 10 Technical papers in National and International Conferences Proceedings/ Journals His research interests include Insulation testing and smart grid

Dr.E.Kaliappan, working as Professor and Head of the Electrical and Electronics Engineering department in Easwari Engineering College, Ramapuram, Chennai, Tamil Nadu. He obtained his PhD. in Special Electrical Machines from Anna University; Chennai. He has more than 19 years of teaching experience and 10 years of research experience. He has published more than 30 papers in International and National journals and presented more than 50 papers in International and national conferences.

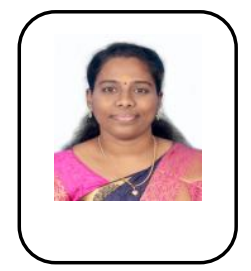

B.Ponkarthika, working as an Assistant Professor in the Department of Electrical and Electronics Engineering, Easwari Engineering College, Chennai, Tamil Nadu, India .She received her B.E degree in Electrical and Electronics Engineering from Saranathan College of Engineering, M.E. degree in Power Electronics and drives from Jerusalem College of Engineering, Anna University, Chennai, India. She has published over 13 Technical papers in National and International Conferences Proceedings/ Journals She has authored one book on Control Systems Engineering. Her research interests include resonant inverters for induction heating and intelligent controllers.

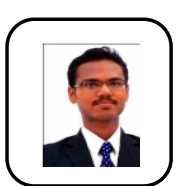

G.Vignesh, working as an Assistant Professor in the Department of Electrical and Electronics Engineering, Easwari Engineering College, Chennai, Tamil Nadu, India .He received his B.E degree in Electrical and Electronics Engineering from Saveetha Engineering College, M.E. degree in Power Electronics and drives from SKR Engineering College, Anna University, Chennai, India. He has also specialized in Clean Energy domain and has completed a course on Solar Energy through Edx from Delft University of Technology, Netherlands. His areas of interest include Power Electronics for Solar PV. Power Conditioners of Wind Turbines, Energy Management and Energy Efficiency 